\title{
Russeting in Apple Seems Unrelated to the Mechanical Properties of the Cuticle at Maturity
}

\author{
Bishnu P. Khanal, Rejina Shrestha, Leonie Hückstädt, \\ and Moritz Knoche ${ }^{1}$ \\ Institute for Horticultural Production Systems, Leibniz-University Hannover, \\ Herrenhäuser Straße 2, 30419 Hannover, Germany
}

Additional index words. Malus, cuticular membrane, wax, strain, fracture, periderm

\begin{abstract}
Russeting is a commercially important disorder of the fruit skin of apples (Malus $\times$ domestica Borkh.). It is thought to result from microscopic cracking of the cuticle on the fruit surface and the subsequent formation of a periderm just below. The study investigates 22 apples cultivars having widely different russeting susceptibilities to determine if susceptibility could be related to the mechanical characteristics of the cuticles at maturity. The mass per unit area of the cuticular membrane (CM), the dewaxed cuticular membrane (DCM), and the cuticle's wax content all varied significantly among the cultivars examined but no simple correlative relationships with russeting susceptibility could be found. Across all cultivars, the mass of wax per unit area was linearly related to $C M$ mass per unit area $(R=0.77, P<0.0001)$. The cuticle of all cultivars was markedly strained as indexed by the release of biaxial strain in the $C M$ on extraction of the wax. The release of biaxial strain was linearly and positively related to wax mass per unit area. Maximum force $\left(F_{\max }\right)$ in uniaxial tensile tests, strain at maximum force $\left(\varepsilon_{\max }\right)$, and the stiffness $(S)$ differed widely among the cultivars tested, but, again, there were no relationships between these mechanical properties and russeting susceptibility. Wax extraction from the CM decreased the $F_{\max }$ in uniaxial tensile tests, increased $\varepsilon_{\max }$, and decreased the $S$. Our results show that none of the cuticle variables measured at maturity nor any of the isolated-cuticle mechanical properties contributes significantly to russeting susceptibility.
\end{abstract}

Russeting is an important disorder of the fruit surface of many fruit crops including apple (Faust and Shear, 1972a, 1972b). In anatomical terms, a russeted area represents an area of periderm comprising phellogen and phellem. The periderm is thought to form in the hypodermal cell layer of developing apple fruit (Meyer, 1944; Verner, 1938). The phellem appears at the fruit surface after the epidermis and cuticle are shed. The phellem's suberized cell walls are responsible for the brownish, dull appearance.

Susceptibility to russeting differs widely among commercial apple cultivars (Faust and Shear, 1972a). Thus, the fruits of some cultivars (e.g., Braeburn) remain essentially russetfree under all growing conditions, whereas in other cultivars (e.g., Egremont Russet), the fruit are almost completely russetted and this is seen as an acceptable cultivar characteristic. However, a large number of cultivars

Received for publication 8 May 2013. Accepted for publication 15 July 2013.

This research was funded in part by a grant from the Niedersächsisches Ministerium für Wissenschaft und Kultur (grant No. 76251-17-4/09/ZN2543).

We thank Friederike Schroeder and Simon Sitzenstock for technical support and Drs. Sandy Lang and Eckhard Grimm for helpful comments on an earlier version of the manuscript.

${ }^{1}$ To whom reprint requests should be addressed; e-mail moritz.knoche@obst.uni-hannover.de. (e.g., Elstar) exhibits russeting only under unfavorable growth conditions. As a result, any russeted fruit of this intermediate cultivar group are usually of reduced market value with potentially serious economic consequences for the grower.

The mechanistic basis for russeting is not clear. Fine, cuticular cracks are considered the first detectable symptom of russeting (Faust and Shear, 1972a). These are thought to result from mechanical failure caused by excessive rates of growth strain, probably during early fruit development (Maguire, 1998; Skene, 1982) and/or from extended exposure to surface moisture (Knoche and Grimm, 2008). Russeting can also be a response to some chemical sprays (Sanchez et al., 2001).

Wax affects the mechanical properties of the cuticle (Dominguez et al., 2011; Petracek and Bukovac, 1995) and this, in turn, may affect susceptibility to russeting in various ways. First, wax prevents the release of biaxial elastic strain by converting reversible elastic into irreversible plastic strain (Khanal et al., 2013a). During growth, the fruit surface enlarges and the cuticle is strained. Because wax acts as a filler in the strained polymer network of the cutin matrix (Petracek and Bukovac, 1995), the deposition of wax essentially "fixes" strain (Khanal et al., 2013a). Second, wax decreases the extensibility of cuticles by increasing their stiffness (Khanal et al., 2013a; Petracek and Bukovac, 1995).
Third, scanning electron microscopy (SEM) studies suggest that wax deposition occurs in microscopic cracks in the cuticle and this may have a healing effect (Curry, 2008; Roy et al., 1999).

Based on these observations, it seems reasonable to hypothesize that differential susceptibility to russeting could be related to certain mechanical properties of the fruit cuticle and the effects of wax thereon. The aim of this study, therefore, was to measure a number of physical properties of the fruit cuticle and also its key mechanical properties (indexed by the release of biaxial strain and the tensile properties of isolated cuticles) in a large number (22) of apple cultivars selected to represent a maximum range in russet susceptibility.

\section{Materials and Methods}

Mature apple (Malus $\times$ domestica Borkh.) fruit were obtained from the following sites: 'Granny Smith' from South Tirol (lat. 46 ${ }^{\circ} 41^{\prime}$ $\mathrm{N}$, long. $11^{\circ} 32^{\prime} \mathrm{E}$ ), Italy; 'Pinova', 'Karmijn de Sonnaville' (hereafter referred to as 'Karmijn'), 'Gala', 'Elstar', and 'Braeburn' from the experimental orchards of the Horticultural Research Station of the Leibniz University at Ruthe (lat. $52^{\circ} 14^{\prime} \mathrm{N}$, long. $9^{\circ} 49^{\prime} \mathrm{E}$ ); and 'Elshof', 'Elstar Boerekamp', 'Golden Delicious Klon B', 'Golden Delicious Reinders', 'Boskoop Green', 'Holsteiner Cox', 'Idared', 'Inacox', 'Jonagold', 'Marina', 'Nicoter', 'Boskoop Red', 'Rubinette', 'Starking', 'Superkalfs', and 'Egremont Russet' from orchards of the Federal Fruit Variety Office at Wurzen (lat. $51^{\circ} 22^{\prime} \mathrm{N}$, long. $12^{\circ} 45^{\prime} \mathrm{E}$ ), Germany. These cultivars were chosen because they are considered to differ markedly in their susceptibility to russet. To enable quantitative analysis, the russet susceptibility of each cultivar was assessed independently on a discrete, 3 -point scale $(0=$ low, $1=$ intermediate, 2 = high) by three industry experts. Where rating scores were available for different regions of the fruit surface, they were all averaged. The mean of these scores was used in the subsequent correlative analyses (Table 1).

Cuticle isolation and wax extraction. $\mathrm{Cu}-$ ticular membranes were isolated enzymatically (Orgell, 1955; Yamada et al., 1964). An epidermal disc (24 mm diameter) comprising cuticle, epidermis, hypodermis, and adhering parenchyma was excised from a russet-free, equatorial region of each fruit. The discs were incubated in $50 \mathrm{~mm}$ citric acid buffer solution $(\mathrm{pH} 4.0)$ containing pectinase $\left[90 \mathrm{~mL} \cdot \mathrm{L}^{-1}\right.$ (Panzym Super E flüssig; Novozymes A/S, Krogshoejvej, Bagsvaerd, Denmark)] and cellulase $\left[5 \mathrm{~mL} \cdot \mathrm{L}^{-1}\right.$ (Cellubrix L.; Novozymes A/S)]. Sodium azide $(30 \mathrm{~mm})$ was added to prevent microbial growth. Enzyme solutions were refreshed periodically over a period of $30 \mathrm{~d}$ until CMs separated from the underlying tissues. Isolated CMs were rinsed thoroughly with deionized water, dried on Teflon sheets, and held at room temperature $\left(22^{\circ} \mathrm{C}\right.$ and $50 \%$ relative humidity). Dewaxed CMs were prepared by Soxhlet extraction of cuticular wax using chloroform/methanol $\left(1: 1 \mathrm{v} / \mathrm{v}, 50{ }^{\circ} \mathrm{C}\right)$ 
Table 1. Russeting susceptibility of 22 apple cultivars, mass of cuticular membrane (CM), dewaxed cuticular membrane (DCM) and wax, calculated wax content of $\mathrm{CM}$, and the release of biaxial strain in the $\mathrm{CM}$ on wax extraction. ${ }^{\mathrm{z}}$

\begin{tabular}{|c|c|c|c|c|c|c|}
\hline \multirow[b]{2}{*}{ Cultivars } & \multirow{2}{*}{$\begin{array}{c}\text { Russet } \\
\text { susceptibility } \\
\text { score }\end{array}$} & \multicolumn{3}{|c|}{ Mass per unit area $\left(\mathrm{g} \cdot \mathrm{m}^{-2}\right)$} & \multirow{2}{*}{$\begin{array}{c}\begin{array}{c}\text { Wax } \\
\text { content }\end{array} \\
(\%)\end{array}$} & \multirow{2}{*}{$\begin{array}{c}\begin{array}{c}\text { Biaxial strain } \\
\text { release }\end{array} \\
(\%)\end{array}$} \\
\hline & & $\mathrm{CM}$ & $\overline{\mathrm{DCM}}$ & Wax & & \\
\hline$\overline{\text { Boskoop Green }}$ & 1.9 & $29.8 \pm 0.6$ & $17.1 \pm 0.3$ & $12.7 \pm 0.2$ & $42.6 \pm 0.2$ & $13.8 \pm 1.0$ \\
\hline Boskoop Red & 1.8 & $9.9 \pm 0.6$ & $17.1 \pm 0.3$ & $12.7 \pm 0.2$ & $+2.6 \pm 0.2$ & $18.3 \pm 0.7$ \\
\hline Braeburn & 0.0 & $1 \pm 0.5$ & $12.0 \pm 0.2$ & $11.1 \pm 0.2$ & $47.9 \pm 0.2$ & $19.1 \pm 0.9$ \\
\hline Egremont Russet & 2.0 & $.2 \pm 1.6$ & $19.2 \pm 1.2$ & $10.0 \pm 0.4$ & $34.5 \pm 0.6$ & $14.5 \pm 1.0$ \\
\hline Elshof & 0.9 & $.2 \pm 0.3$ & $14.2 \pm 0.2$ & $11.0 \pm 0.1$ & $3.5 \pm 0.2$ & $14.4 \pm 0.9$ \\
\hline Els & 0.9 & $8 \pm 0.1$ & $14.6 \pm 0.1$ & $11.2 \pm$ & $.3 \pm 0.3$ & $3.6 \pm 0.6$ \\
\hline Elstar I & 0.8 & $9 \pm 0.5$ & $14.8 \pm 0.4$ & $11.1 \pm 0.2$ & $.8 \pm 0.5$ & $5.4 \pm 0.7$ \\
\hline Gala & 0.7 & $6 \pm 0.4$ & $11.7 \pm 0.2$ & $10.9 \pm 0.2$ & $8.2 \pm 0.2$ & $8.7 \pm 0.9$ \\
\hline Golden D. Klon B & 1.2 & $1 \pm 0.4$ & $17.9 \pm 0.3$ & $12.2 \pm 0.3$ & $40.4 \pm 0.7$ & $12.7 \pm 0.6$ \\
\hline Reinders & 0.8 & \pm 0.9 & 0.5 & 14 & $.8 \pm 0.2$ & $15.2 \pm 0.8$ \\
\hline & 0.3 & $1 \pm 0.4$ & $1 \pm 0.2$ & 11 & $.7 \pm 0.3$ & $.9 \pm 0.4$ \\
\hline & 6 & $8 \pm 0.2$ & 1 & 12. & $.4 \pm 0.2$ & $15.0 \pm 0.5$ \\
\hline Ida & 0.4 & $3 \pm 0.3$ & $11.3 \pm 0.1$ & $8.9 \pm 0.2$ & $4.1 \pm 0.2$ & $9.6 \pm 0.9$ \\
\hline & 0.9 & $9 \pm 0.3$ & $13.5 \pm 0.2$ & $12.4 \pm 0.2$ & $47.8 \pm 0.5$ & $19.1 \pm 0.8$ \\
\hline Jona & 0.4 & $2 \pm 0.4$ & $15.2 \pm 0.2$ & $13.1 \pm 0.2$ & $46.3 \pm 0.2$ & $15.2 \pm 0.9$ \\
\hline & 1.8 & $0 \pm 0.1$ & $13.0 \pm 0.2$ & & $48.0 \pm 0.6$ & $20.4 \pm 1.1$ \\
\hline & 0 & \pm 0.2 & & & $.4 \pm 0.3$ & $13.6 \pm 0.7$ \\
\hline & & $2 \pm 0.5$ & 3 & 2 & $.4 \pm 0.2$ & $15.2 \pm 0.9$ \\
\hline & 1. & $8 \pm 0.5$ & $12.8 \pm 0.3$ & $13.1 \pm$ & $50.6 \pm 0.3$ & $23.4 \pm 1.2$ \\
\hline & 0.8 & $.0 \pm 0.3$ & $15.9 \pm 0.2$ & $14.1 \pm 0.1$ & $47.0 \pm 0.2$ & $20.5 \pm 0.8$ \\
\hline Starking & 0.1 & $30.9 \pm 0.8$ & $17.8 \pm 0.5$ & $13.1 \pm 0.3$ & $42.5 \pm 0.2$ & $16.1 \pm 1.0$ \\
\hline Superkalfs & 1.6 & $28.4 \pm 0.5$ & $16.2 \pm 0.3$ & $12.2 \pm 0.2$ & $42.9 \pm 0.2$ & $15.4 \pm 1.0$ \\
\hline Grand mean & & $26.7 \pm 0.3$ & $14.9 \pm 0.2$ & $11.9 \pm 0.1$ & $44.6 \pm 1.8$ & $16.0 \pm 0.2$ \\
\hline
\end{tabular}

${ }^{2}$ Russet susceptibility was indexed by averaging three, independent scores $(0=$ not susceptible, $1=$ intermediate, 2 = susceptible) offered by three industry specialists. The release of biaxial strain was indexed by the fractional decrease in area of the CM disc on wax extraction. For further details, see text.

for $2.5 \mathrm{~h}$. Cuticle mass and wax mass per unit area were established gravimetrically on an analytical balance (CPA2P Sartorius AG Germany) with five replications, where one replicate comprised five pooled $\mathrm{CM}$ or DCM discs (24 mm diameter).

Strain relaxation assay. The release of biaxial strain $\left(\varepsilon_{\text {biaxial }}\right)$ from $\mathrm{CMs}$ after wax extraction was quantified as described previously (Khanal et al., 2013a). Briefly, a square pattern of four holes $(\approx 3.25 \mathrm{~mm} \times$ $3.25 \mathrm{~mm}$, hole diameter $\approx 0.5 \mathrm{~mm}$ ) was punched in untreated $\mathrm{CM}$ discs $(8 \mathrm{~mm}$ diameter). The area enclosed by the square pattern was quantified both before $\left(A_{C M}\right)$ and after $\left(A_{D C M}\right)$ wax extraction using calibrated digital images taken at $\times 1.25$ magnification using a dissecting microscope (MZ10F; Leica Microsysteme GmbH, Wetzlar, Germany; camera DP71; Olympus) and image analysis (Software Cell^P; Olympus). The release of biaxial strain $\left(\varepsilon_{\text {biaxial }} ; \%\right)$ was calculated as:

$$
\varepsilon_{\text {biaxial }}=\frac{A_{C M}-A_{D C M}}{A_{D C M}} \times 100
$$

Tensile test. Strips (5 mm wide) were excised from CM or DCM discs $(24 \mathrm{~mm}$ diameter) using parallel razor blades. The strips were then stabilized by mounting in a frame made from paper and masking tape (Tesa Krepp $^{\mathrm{R}}$; tesa Werk Hamburg GmbH, Hamburg, Germany) to avoid imposing unintentional strain before the tensile tests were initiated. Specimens were fully hydrated by incubating in deionized water at $22{ }^{\circ} \mathrm{C}$ for $16 \mathrm{~h}$. Subsequently, frames were mounted between the clamps of a universal material testing machine (Z 0.5; Zwick Roell, Ulm, Germany). The distance between the clamps
$\left(L_{0}\right)$ was $10 \mathrm{~mm}$. Paper frames were then cut open and the tensile tests initiated (crosshead speed $1 \mathrm{~mm} \cdot \mathrm{min}^{-1}$ ) until failure occurred. The forces applied (10 N, standard force transducer) and the corresponding specimen lengths $(L)$ were recorded. The $F_{\text {max }}$ (Newtons) that closely resembled the force at failure was obtained from the recorded data. Strain (\%) was calculated as:

$$
\varepsilon_{\max }=\frac{L-L_{0}}{L_{0}} \times 100
$$

This $\varepsilon_{\max }$ correspond to the strain at $F_{\max }$. Stiffness (Newtons) was determined as the maximum slope of a linear regression fitted through a plot of force (Newtons) vs. fractional strain (percent/100). Data for specimens that failed in, or adjacent to, the clamps were excluded from the analyses. Also excluded were any specimens that exhibited irregular force-vs.-displacement curves. The excluded results were $\approx 17 \%$ of the total population. The number of replicates ranged from 10 to 15 .

Data analyses. The $S$ (Newtons) we refer to throughout this article reflects the properties of the CM with or without wax. It differs from the modulus of elasticity $(E ; \mathrm{MPa})$ commonly used in engineering in that it is not based on the sample cross-sectional area but on the sample width (sample thickness is undefined). Data were subjected to correlation (Proc Corr) and regression analysis (Proc Reg) using SAS (Version 9.1.3; SAS Institute, Cary, NC). The data in the figure and tables are presented as means and sEMs. Where not shown, the error bars are smaller than the symbols.

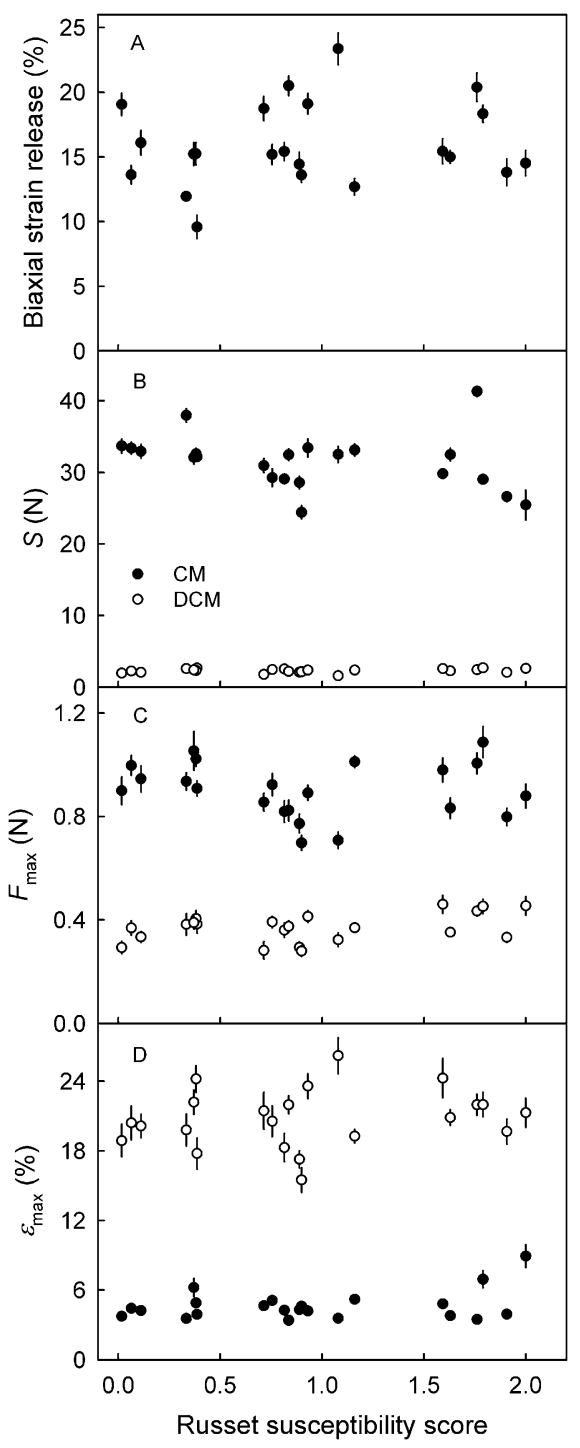

Fig. 1. Mechanical properties of isolated cuticular membranes (CMs) of 22 apple cultivars in relation to their russet susceptibility. Russet susceptibility was indexed by averaging three, independent scores $(0=$ not susceptible, $1=$ intermediate, 2 = susceptible) offered by three industry specialists. Release of biaxial strain in the CM on wax extraction vs. russet susceptibility score (A). Stiffness $(S ; \mathbf{B})$, maximum force $\left(F_{\max } ; \mathbf{C}\right)$, and strain at maximum force $\left(\varepsilon_{\max } ; \mathbf{D}\right)$ of CM and dewaxed CM (DCM) of 22 apple cultivars vs. russet susceptibility score.

\section{Results}

Mass per unit area of CM, DCM, and wax varied significantly among the cultivars (Table 1). CM, DCM, and wax mass per unit area were lowest in 'Idared' and highest in 'Golden Delicious Reinders'. The wax content was lowest in 'Egremont Russet' and highest in 'Pinova'. Across all cultivars, wax mass per unit area was linearly related to $C M$ mass per unit area $(R=0.77, P<0.0001)$. In all cultivars, wax extraction released biaxial strain in the CM. The release of biaxial strain was lowest in 'Idared' and highest in 'Pinova'. There was no significant (linear) relationship between russet susceptibility and cuticle mass 
Table 2. Relationships among selected physical properties of cuticular membrane (CM), dewaxed cuticular membrane (DCM), and the change in physical properties on wax extraction (CM-DCM) and the russet susceptibility of 22 selected apple cultivars. ${ }^{\mathrm{z}}$

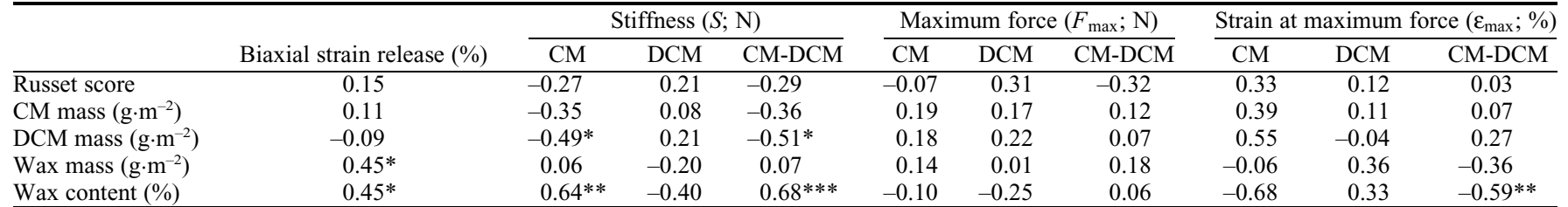

${ }^{2}$ Relationships were indexed by Pearson's coefficients of correlation. Russet susceptibility was indexed by averaging three, independent scores $(0=$ not susceptible, $1=$ intermediate, $2=$ susceptible) offered by three industry specialists.

Significance of Pearson's correlation coefficient $(R)$ for $* P<0.05, * *<0.01$, and $* * *<0.001$.

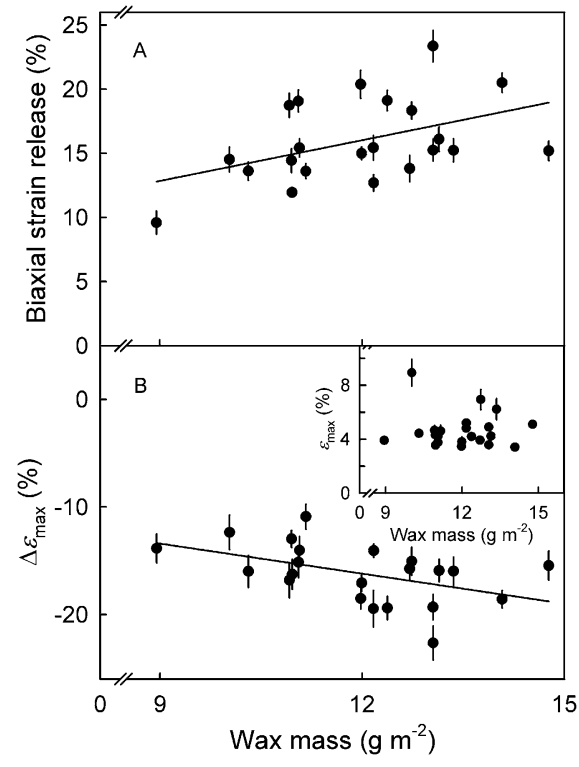

Fig. 2. Effect of wax on the mechanical properties of cuticular membranes (CMs) isolated from a number of apple cultivars selected for their wide-ranging susceptibilities to russet. Release of biaxial strain in $\mathrm{CM}$ on wax extraction as a function of the mass of wax extracted (A) Change in maximum strain $\left(\Delta \varepsilon_{\max } ; \mathbf{B}\right)$ of the $\mathrm{CM}$ on wax extraction in relation to the mass of wax extracted per unit area. $\varepsilon_{\max }$ of the $\mathrm{CM}$ as a function of the mass of wax extracted $(B$; inset).

( $R=0.29 ; P=0.18)$ or wax mass $(R=0.09$; $P=0.70$ ) or the release of biaxial strain (Fig. 1A; Table 2). The release of biaxial strain was linearly and positively related to wax mass per unit area (Fig. $2 \mathrm{~A} ; R^{2}=0.21, P=0.033$ ).

The $S$ established in uniaxial tensile tests ranged from a low of $24.4 \pm 0.9 \mathrm{~N}$ for 'Elstar' $\mathrm{CM}$ to a high of $41.3 \pm 0.7 \mathrm{~N}$ for 'Karmijn' $\mathrm{CM}$. It ranged from a low of $1.6 \pm 0.1 \mathrm{~N}$ for 'Pinova' DCM to a high of $2.7 \pm 0.1 \mathrm{~N}$ for 'Idared' DCM (Table 3). Extraction of cuticular wax markedly decreases the $S$ of the cuticle in all cultivars (Table 3 ). However, neither the value taken by $S$ nor the decrease in $S$ on wax extraction was significantly related to russet susceptibility (Fig. 1B; Table 2).

The $F_{\max }$ values of the CMs and DCMs ranged from $0.70 \pm 0.03 \mathrm{~N}$ (CM; 'Elstar') to $1.09 \pm 0.06 \mathrm{~N}$ (CM; 'Boskoop Red') and from $0.28 \pm 0.02 \mathrm{~N}$ (DCM; 'Elstar') to $0.46 \pm 0.04 \mathrm{~N}$ (DCM; 'Superkalfs'). Wax extraction usually decreased $F_{\max }$ by approximately half (Table 3 ).

Table 3. Mechanical properties of fruit cuticular membrane (CM) and dewaxed cuticular membrane (DCM) isolated from various apple cultivars selected for a maximum range of russet sensitivity. ${ }^{\mathrm{z}}$

\begin{tabular}{|c|c|c|c|c|c|c|}
\hline \multirow[b]{2}{*}{ Cultivars } & \multicolumn{2}{|c|}{$S(\mathrm{~N})$} & \multicolumn{2}{|c|}{$F_{\max }(\mathrm{N})$} & \multicolumn{2}{|c|}{$\varepsilon_{\max }(\%)$} \\
\hline & $\mathrm{CM}$ & DCM & $\mathrm{CM}$ & DCM & $\mathrm{CM}$ & DCM \\
\hline Boskoop Green & $26.6 \pm 0.7$ & $2.1 \pm 0.1$ & $.80 \pm 0.03$ & $0.33 \pm 0.02$ & $3.9 \pm 0.2$ & $19.7 \pm 1.1$ \\
\hline Boskoop Red & $9.0 \pm 0.6$ & $2.7 \pm 0.1$ & $09 \pm 0.06$ & $0.45 \pm 0.03$ & $6.9 \pm 0.7$ & $22.0 \pm 1.1$ \\
\hline Braeburn & $.7 \pm 1.0$ & $2.0 \pm 0.1$ & $90 \pm 0.05$ & $0.29 \pm 0.02$ & $3.8 \pm 0.3$ & $18.9 \pm 1.4$ \\
\hline Egremont Russet & $5.5 \pm 2.1$ & $2.6 \pm 0.2$ & $.88 \pm 0.05$ & $0.45 \pm 0.04$ & $8.9 \pm 1.0$ & $21.3 \pm 1.3$ \\
\hline Elshof & $.6 \pm 0.9$ & $2.1 \pm 0.1$ & $77 \pm 0.04$ & $0.29 \pm 0.02$ & $.3 \pm 0.3$ & $17.3 \pm 0.7$ \\
\hline Elstar & $4 \pm 0.9$ & $2.1 \pm 0.1$ & $0 \pm 0.03$ & $0.28 \pm 0.02$ & $.6 \pm 0.4$ & $5.5 \pm 1.1$ \\
\hline erekamp & $1 \pm 0.7$ & $2.5 \pm 0.1$ & $2 \pm 0.04$ & $0.36 \pm 0.03$ & $4.3 \pm 0.4$ & $3 \pm 1.2$ \\
\hline Gala & $.9 \pm 1.0$ & $1.8 \pm 0.2$ & $86 \pm 0.03$ & $0.28 \pm 0.03$ & $4.7 \pm 0.4$ & $21.5 \pm 1.6$ \\
\hline Klon B & $1 \pm 0.9$ & $2.4 \pm 0.1$ & $01 \pm 0.02$ & $0.37 \pm 0.02$ & $5.2 \pm 0.2$ & $19.3 \pm 0.6$ \\
\hline D. Reinders & $.3 \pm 1.3$ & $2.5 \pm 0.1$ & $2 \pm 0.04$ & $0.39 \pm 0.02$ & $.1 \pm 0.2$ & $20.6 \pm 1.3$ \\
\hline & \pm 0.9 & $2.6 \pm 0.2$ & $4 \pm 0.03$ & $8 \pm 0.04$ & $.6 \pm 0.2$ & $9.8 \pm 1.4$ \\
\hline $\mathrm{H}$ & $5 \pm 0.9$ & $2.3 \pm 0.1$ & $3 \pm 0.04$ & $0.35 \pm 0.02$ & $8 \pm 0.4$ & $20.9 \pm 0.7$ \\
\hline Id & $.2 \pm 0.4$ & $2.7 \pm 0.1$ & $91 \pm 0.03$ & $0.38 \pm 0.04$ & $3.9 \pm 0.2$ & $17.8 \pm 1.3$ \\
\hline In & $.4 \pm 1.3$ & $2.4 \pm 0.1$ & $89 \pm 0.03$ & $0.41 \pm 0.02$ & $4.2 \pm 0.3$ & $23.6 \pm 1.1$ \\
\hline & $.6 \pm 0.8$ & $2.3 \pm 0.1$ & $.02 \pm 0.03$ & $0.41 \pm 0.03$ & $4.9 \pm 0.2$ & $24.2 \pm 1.2$ \\
\hline $\mathrm{Ka}$ & $.3 \pm 0.7$ & $2.4 \pm 0.1$ & $01 \pm 0.04$ & $0.43 \pm 0.02$ & $3.5 \pm 0.2$ & $22.0 \pm 0.9$ \\
\hline & $4 \pm 0.8$ & $3 \pm 0.1$ & \pm 0.04 & $0.37 \pm 0.03$ & $4.4 \pm 0.3$ & $20.4 \pm 1.5$ \\
\hline & $1 \pm 0.9$ & $2.4 \pm 0.1$ & $5 \pm$ & $0.39 \pm 0.03$ & $6.2 \pm 0.8$ & $22.2 \pm 1.1$ \\
\hline & $.5 \pm 1.1$ & $1.6 \pm 0.1$ & $71 \pm 0.03$ & $0.32 \pm 0.03$ & $3.6 \pm 0.3$ & $26.2 \pm 1.6$ \\
\hline & $.5 \pm 0.8$ & $2.2 \pm 0.1$ & $82 \pm 0.04$ & $0.37 \pm 0.02$ & $3.4 \pm 0.2$ & $22.0 \pm 0.8$ \\
\hline Starking & $.9 \pm 1.0$ & $2.1 \pm 0.1$ & $.94 \pm 0.05$ & $0.33 \pm 0.02$ & $4.2 \pm 0.3$ & $20.1 \pm 1.0$ \\
\hline Superkal & $.8 \pm 0.5$ & $2.6 \pm 0.1$ & $98 \pm 0.05$ & $0.46 \pm 0.04$ & $4.8 \pm 0.3$ & $24.3 \pm 1.7$ \\
\hline Grand mean & $31.6 \pm 0.3$ & $2.3 \pm 0.03$ & $0.90 \pm 0.01$ & $0.37 \pm 0.01$ & $4.6 \pm 0.1$ & $20.8 \pm 0.3$ \\
\hline
\end{tabular}

${ }^{2}$ Maximum force $\left(F_{\max }\right)$, strain at maximum force $\left(\varepsilon_{\max }\right)$, and stiffness $(S)$ were quantified from uniaxial tensile test using fully hydrated specimens.

There was no significant relationship between $F_{\max }$ or the change in $F_{\max }$ on wax extraction and russet susceptibility (Fig. 1C; Table 2).

The $\varepsilon_{\max }$ values ranged from $3.4 \% \pm 0.2 \%$ (CM; 'Rubinette') to $8.9 \% \pm 1.0 \%(\mathrm{CM}$; 'Egremont Russet') and from 15.5\% $\pm 1.1 \%$ (DCM; 'Elstar') to $26.2 \% \pm 1.6 \%$ (DCM; 'Pinova'). On average, wax extraction increased $\varepsilon_{\max } \approx 5$-fold (Table 3 ). Neither $\varepsilon_{\max }$ nor the change in $\varepsilon_{\max }$ on wax extraction were significantly related to russet susceptibility (Fig. 1D; Table 2). The increase in $\varepsilon_{\max }$ on wax extraction was significantly greater for those cultivars that had more wax per unit area in their CM (Fig. 2B) $\left(R^{2}=0.23 ; P=\right.$ $0.026)$. However, there was no significant relationship between $\varepsilon_{\max }$ and the amount of wax (Fig. 2B, inset).

\section{Discussion}

There were no significant relationships between a cultivar's russet susceptibility and any of the characteristics of their CM's investigated at maturity. It is therefore reasonable to infer that factors other than the CM's mechanical properties reported here dominate in determining russeting suscepti- bility among the 22 apple cultivars examined here. Alternatively, changes in CM properties that have occurred between near bloom and fruit maturity may have masked their relation to russet formation. However, at present there is no evidence for this being the case. Several conclusions emerge.

First, it would seem reasonable to infer that the cuticle is not the load-bearing structure of an apple fruit skin. Instead, load bearing would seem to be sustained primarily within the epidermal and hypodermal cell layers (Khanal et al., 2013b). It can be speculated that if there were any periclinal variations in the efficacy of the structural support of the CM afforded by the underlying epidermal and hypodermal layers, then this might cause stress concentration and thus premature failure of the CM in the less wellsupported zones. This scenario might occur more frequently in the russet-susceptible cultivars. It may also be speculated that such variation could arise from changes in the orientation of the cellulose fibrils in the cell walls of the periclinal surfaces of the epidermal cell walls or from the presence of a viscous, pectic middle lamellae between abutting anticlinal epidermal cell walls. These are oriented 
perpendicular to the direction of maximum tension. Also, epidermal and hypodermal cells are known to elongate during fruit growth (Meyer, 1944). Maguire (1998) hypothesized that during the periclinal elongation of apple's epidermal cells, abutting portions of two epidermal cells' anticlinal walls peel apart and reorientate to form extensions of their periclinal walls. This would likely focus strain in the $\mathrm{CM}$ at a point immediately above the anticlinal epidermal cell walls (Maguire, 1998). These observations are consistent with the characteristic pattern of cuticular cracks in apple fruit often observed in SEM studies (Curry, 2008; Roy et al., 1999). To our knowledge, there is no quantitative information available on any of these properties relating to apple cultivars of differing russet susceptibility.

Second, the apple cuticle may itself be mechanically non-homogeneous. For example, cuticle thickness is variable over the surface of a fruit and especially between cultivars. In some cultivars, cuticles even encase one or several cell layers (Meyer, 1944; Miller, 1982). Also, microcracks occur in the apple cuticle and these are likely to alter the mechanical properties of the isolated CM (Knoche and Grimm, 2008; Knoche et al., 2011; Maguire et al.; 1999).

Third, polysaccharides such as cellulose and pectins are also constituents of cuticles (Schreiber and Schönherr, 1990) and thus are potentially important covariables that may determine the rheological properties of the cuticle (Dominguez et al., 2011; LopézCasado et al., 2007). If any of these factors varied among the apple cultivars investigated here, this might have weakened any relationships between the CM's mechanical properties and their russet susceptibility.

Fourth, in this study, we have focused on measurements made on CMs at fruit maturity, whereas it is during the first 4 weeks after full bloom that conditions are considered to be the most important for russeting (Knoche et al., 2011; Wertheim, 1982).

Finally, the effect of wax on russeting may, itself, be more complex and its influence not restricted to altered mechanical properties. For example, there is evidence that wax is deposited in the cracks of the cuticles (Curry, 2008; Roy et al., 1999). This is not considered unlikely, because the diffusion resistance experienced by wax constituents migrating from their site of synthesis (in the epidermal cells) to the outer surface of the cuticle would presumably be least over the shorter distance to the base of a crack. This being the case, the natural "filling" or "healing" of any cuticular cracks might keep pace with their rate of formation with the result that a periderm need not be formed and the temporary cuticular defect (microcrack) might pass unnoticed having no further consequence.

The effect of wax on the mechanical properties of the apple fruit CM was consistent among the cultivars investigated. In all 22 cultivars, wax extraction 1 ) released the biaxial strain in the $\mathrm{CM}$;2) it decreased $S ; 3$ ) it decreased $F_{\max }$; and 4 ) it increased $\varepsilon_{\max }$. These changes are also consistent with previous observations (Khanal et al., 2013a), in which the release of biaxial strain in the $\mathrm{CM}$ and the change in $\varepsilon_{\max }$ on wax extraction were both related to the amount of wax. Compared with the $\mathrm{CM}$ of tomato fruit (Lopéz-Casado et al., 2007; Matas et al., 2004; Petracek and Bukovac, 1995), that of apple was thicker and stiffer, and fracture force was lower.

In summary, from our results, there is no indication of a simple relationship between an apple cultivar's russet susceptibility and the mechanical properties of its fruit cuticle at maturity and the effects of wax thereon.

\section{Literature Cited}

Curry, E.A. 2008. Effects of 1-MCP applied postharvest on epicuticular wax of apples (Malus domestica Borkh.) during storage. J. Sci. Food Agr. 88:996-1006.

Dominguez, E., J. Cuartero, and A. Heredia. 2011. An overview on plant cuticle biomechanics. Plant Sci. 181:77-84.

Faust, M. and C.B. Shear. 1972a. Russeting of apples, an interpretive review. HortScience 7:233-235.

Faust, M. and C.B. Shear. 1972b. Fine structure of the fruit surface of three apple cultivars. J. Amer. Soc. Hort. Sci. 97:351-355.

Khanal, B.P., E. Grimm, S. Finger, A. Blume, and M. Knoche. 2013a. Intracuticular wax fixes and restricts strain in leaf and fruit cuticles. New Phytol. doi: 10.1111/nph.12355.

Khanal, B.P., E. Grimm, and M. Knoche. 2013b. Russeting in apple and pear: A plastic periderm replaces a stiff cuticle. AoB Plants 5:Pls048. doi: 10.1093/aobpla/pls048.

Knoche, M. and E. Grimm. 2008. Surface moisture induces microcracks in the cuticle of 'Golden Delicious' apple. HortScience 43:1929-1931.
Knoche, M., B.P. Khanal, and M. Stopar. 2011. Russeting and microcracking of 'Golden Delicious' apple fruit concomitantly decline due to gibberellin A4+7 application. J. Amer. Soc. Hort. Sci. 136:159-164.

Lopéz-Casado, G., A.J. Matas, E. Dominguez, J. Cuartero, and A. Heredia. 2007. Biomechanics of isolated tomato (Solanum lycopersicum L.) fruit cuticles: The role of the cutin matrix and polysaccharides. J. Expt. Bot. 58:38753883.

Maguire, K.M. 1998. Factors affecting mass loss of apples. PhD thesis, Massey University, New Zealand.

Maguire, K.M., A. Lang, N.H. Banks, A. Hall, D. Hopcroft, and R. Bennett. 1999. Relationship between water vapour permeance of apples and micro-cracking of the cuticle. Postharvest Biol. Technol. 17:89-96.

Matas, A.J., E.D. Cobb, J.A. Bartsch, D.J. Paolillo, and K.J. Niklas. 2004. Biomechanics and anatomy of Lycopersicon esculentum fruit peels and enzyme-treated samples. Amer. J. Bot. 91:352360.

Meyer, A. 1944. A study of the skin structure of 'Golden Delicious' apples. Proc. Amer. Soc. Hort. Sci. 45:105-110.

Miller, R.H. 1982. Apple fruit cuticles and the occurrence of pores and transcuticular canals. Ann. Bot. (Lond.) 50:355-371.

Orgell, W.H. 1955. The isolation of plant cuticle with pectic enzymes. Plant Physiol. 30:78-80.

Petracek, P.D. and M.J. Bukovac. 1995. Rheological properties of enzymatically isolated tomato fruit cuticle. Plant Physiol. 109:675-679.

Roy, S., W.S. Conway, A.E. Watada, C.E. Sams, E.F. Erbe, and W.P. Wergin. 1999. Changes in the ultrastructure of the epicuticular wax and postharvest calcium uptake in apples. HortScience 34:121-124.

Sanchez, E., J.M. Soto, J.X. Uvalle, A.P. Hernandez, J.M. Ruiz, and L. Romero. 2001. Chemical treatments in 'Golden Delicious Spur' fruits in relation to russeting and nutritional status. J. Plant Nutr. 24:191-202.

Schreiber, L. and J. Schönherr. 1990. Phase transitions and thermal expansion coefficients of plant cuticles: The effects of temperature on structure and function. Planta 182:186-193.

Skene, D.S. 1982. The development of russet, rough russet and cracks on the fruit of the apple Cox's Orange Pippin during the course of the season. J. Hort. Sci. 57:165-174.

Verner, L. 1938. Histology of apple fruit tissue in relation to cracking. J. Agr. Res. 57:813-824.

Wertheim, S.J. 1982. Fruit russeting in apple as affected by various gibberellins. J. Hort. Sci. 57:283-288.

Yamada, Y., S.H. Wittwer, and M.J. Bukovac. 1964. Penetration of ions through isolated cuticles. Plant Physiol. 39:28-32. 